\title{
Designing Educational Videos for University Websites Based on Students' Preferences
}

\author{
Zainab Hameed Alfayez \\ Department of Computer Information Systems, \\ College of Computer Science and Information Technology, University of Basrah, Basrah, Iraq
}

\begin{abstract}
Recent developments have seen a significant increase in the number of educational videos being made, mostly for use as a resource in a range of educational levels and different specializations. Indeed, currently, many universities either provide videos as supplementary resources or, indeed, offer entire courses as online learning materials. The qualitative study this paper presents was conducted to answer the following questions: "How have educational videos (lectures/tutorials) published on YouTube affected the university students' studies at both postgraduate and undergraduate levels?" and "would it be better to upload these types of videos onto a university website?" The aim was to explore the experiences of students from two universities (one a highranking university and one from a developing country) regarding online educational videos and to assess the extent to which these kinds of videos influence their studies. The data collection method used was individual interviews with students from two different universities to gather their perspectives, their opinions, and their aspirations regarding such videos. The results section analyzes and discusses the students' varied opinions. Based on the research findings, several recommendations are made to develop a useable design to add videos to university websites. Finally, the research discussed how this study's findings contribute during the COVID-19 pandemic.
\end{abstract}

Keywords: educational videos, design, computer-based learning, universities website, student preferences

Alfayez, Z.H. (2021). Designing educational videos for university websites based on students' preferences. Online Learning, 25(2), 280-298. https://doi.org/10.24059/olj.v25i2.2232 


\section{Designing Educational Videos for University Websites Based on Students' Preferences}

Technology is now a crucial aspect of many areas of our existence, one of which is education. Advances in information and communication technologies have led to the emergence of new tools that have been incorporated into a range of learning strategies. Technology is a powerful tool that educators use to present a range of information on a specific topic. In addition, it enables them to include material that is not available in print or that would require synthesis from a range of resources (Marshall, 2002). Recently, computer-assisted learning (CAL) has become very popular. CAL refers to using computers to present information in such a way that increases the efficiency of the traditional methods of education (lectures, exercises, and laboratories) (Karakas \& Tekindal, 2008). However, while CAL is based on text, the multimedia within CAL allows the combination of text, audio, graphic images, and video (Cooper, 2007).

The current increase in the use of multimedia in the learning sector has been accompanied by a surge in the popularity of online educational videos Educators, whether anonymous or wellknown, have been able to exploit websites in the format of a video that has been recorded by educators. This kind of CAL is the focus of this research.

The study's main aim is to investigate the students' experiences with educational videos (lectures and tutorials) that are made available on the internet. Thus, these videos are discussed from different usability aspects, including general styling and visual rendering, and the benefits and drawbacks of including videos on the university website are explored. The paper's findings are based on data gathered from a study conducted on students of the University of Basrah and Swansea University. The students commented about their experiences with online videos in general and the way such videos might influence their studies. Finally, the research offers various recommendations on how to develop suitable videos for uploading to the university website as a resource to benefit the students.

\section{Background}

YouTube, which hosts many different kinds of videos, is the world's most popular website, as it allows anyone to upload a video and share it with other people and to view videos by others (Kunjambu \& Muniandy, 2013). Three PayPal employees, Chad Hurley, Steve Chen, and Jawed Karim, founded YouTube on February 14, 2005, when it was activated under the URL "www.youtube.com" (Kunjambu \& Muniandy, 2013). The website uses technologies like WebM, H.264, and Adobe Flash Video to show a range of videos made by a many different users. The first YouTube video was uploaded by Jawed Karim in April 2005 (YouTube, 2020). Titled "Me at the zoo," it lasted 19 seconds. Since then, the site has expanded rapidly in both the viewing and uploading of videos. The most recent YouTube statistics in 2019 state that "Over 2 billion loggedin users visit YouTube each month and every day, people watch over a billion hours of video and generate billions of views" (YouTube, 2020). This growth demonstrates the website's effectiveness and accessibility, with YouTube easily available to users globally and on a variety of platforms (YouTube, 2020). Moreover, the site has kept pace with the massive advancements in technology, meaning videos can now be viewed on various devices like tablets, mobile phones, and so on (YouTube, 2020). Videos are mostly uploaded by individuals; however, some branches of the media and organizations, for example, the BBC and Vevo, incorporate and offer materials via the YouTube website. YouTube contents include TV clips, music videos, video clips, and various other types of content, such vlogs and educational videos. 
YouTube's popularity and seamless access has encouraged academics and educators to use the educational YouTube domain (www.youtube.com/education) to share their knowledge. This domain contains a huge number of videos, and these are classified or grouped under the relevant discipline, such as medicine, social sciences, math, engineering, and so on, or according to the educational level (e.g., university, secondary, and primary). The innovation of the face-to-face communication and the ease of use of this kind of technology has helped accelerate scientific advancements and has revolutionized online video learning. Indeed, several schools and online courses have been founded on the YouTube platform.

Two popular examples of the use of YouTube for publishing educational videos to learners worldwide are Academic Earth and Khan Academy. They offer both short lectures and long videos. Even though Academic Earth publishes lectures from instructors at many highly acclaimed institutions, Khan Academy has achieved greater popularity and received more attention from both the media and from learners (Scagnoli, McKinney, \& Moore-Reynen, 2015).

Teachers are advised to apply Khan Academy to build and maintain clear lines of contact with students (Vidergor \& Ben-Amram, 2020). It was proved that Khan Academy encourages independency, always available, and more interesting than books (Vidergor \& Ben-Amram, 2020). This led to YouTube becoming an Open Educational Resource whereby educational resources can be accessed through information and communications technologies (Martinho \& Pinto, 2012).

Moreover, YouTube contains thousands of channels owned by anonymous users, who create video lessons on one or more topics to share their knowledge. For example, Khan Academy allows instructors to share their expertise, irrespective of whether they can demonstrate affiliation with a prestigious university (Scagnoli et al., 2015). It should be noted, however, that some studies have claimed that the material on YouTube is inaccurate: "YouTube material is a poor source of accurate information" (Abdelmseih, 2016); "contents are of unknown source and accuracy" (Ferhatoglu, Kartal, Ekici, \& Gurkan, 2019); "videos offered poor information quality, reliability, and accuracy" (Springer, Bechler, Koller, Windhager, \& Waldstein, 2020). Nonetheless, there can be thousands or even millions of views for such videos.

The success of the website combined with the claims of inaccuracy has led to several challenges, for example, the critical selection of relevant material with an educational value from among thousands of open access videos, the range of types of videos, and the sources for choosing videos, (Berk, 2009), (Jones \& Cuthrell, 2011). Furthermore with regard to the selection criteria, several issues should be considered, such as the students' characteristics, the video's message, and the video's structure, including actions, context, length, characters, and visual cues (Berk, 2009). In addition, YouTube offers no guarantee of the video's availability, meaning that, at any time, "an author" or site administrator can add or delete videos from the site (Cha, Kwak, Rodriguez, Ahn, \& Moon, 2007).

Given these challenges, the information these videos offer cannot be trusted because anyone is authorized to publish a video, even though their lack of experience can make them unqualified to explain the topic adequately. The huge number of videos on identical topics can confuse the student, who will spend much of their time trying to find the suitable video that matches their topic of interest. Therefore, it would be better for students if they were directly given suitable videos that matched their studies and if they had easy access via the university website, particularly if these videos were designed based on their preferences. 


\section{Review of Relevant Literature}

Before launching of YouTube, there had been several attempts to include videos in the learning process. For example, in 2001, Latchman \& Latchman proposed a method called "Lectures-on-Demand," which allows students to have access to online streaming audio and video synchronized with the class materials. The authors discussed the technical requirements from the perspective of the user and provider, such as the type and the speed of the internet service. The result showed that 34 students who took an on-campus course via available video lectures had higher scores on quizzes than students who did not use the online video lectures. Besides that, $58 \%$ of students preferred the "Lectures-on-Demand" method, as it has more interaction than regular classes.

Another study was conducted in 2002 by Foertsch, Moses, Strikwerda, \& Litzkow, who developed a multimedia web-based application called eTEACH and used it to replace in-class lectures with videotaped lectures that students could view on the internet. Over two semesters, a thorough evaluation of the computer science course revealed students who had the online lectures gave a significantly high rating to several course aspects like the quality of the lessons, the responsiveness of the lecturers, and the overall course. The results of the survey, based on 531 students, showed that two-thirds of them understood the information in the lectures given through the eTEACH application better than they would have when attending classroom lectures. Moreover, $78 \%$ of the students enjoyed the opportunity to show and revisit lectures in their own time.

The launching of YouTube in 2005 and the evolution of new educational environments like Massive Open Online Courses (MOOCs) motivated authors to explore how video resources might improve participants' self-learning and develop them as learners. For example, Guo, Kim, $\&$ Rubin (2014) presented a theoretical study about students' engagement; they investigated how MOOC video productions (lectures and tutorials) could affect this engagement. The paper discussed various styles of video productions; for example, classroom lecture, "talking head" (shot of an instructor at a desk), and PowerPoint slide presentations. Their findings were based on an analysis of both quantitative and qualitative data. Based on the qualitative data, they offered the video producers and instructors recommendations for developing the format of these videos and making them more effective for the audience: each video should be under six minutes; the tutor or the instructor should appear at appropriate times in the video; rather than in big studios, the video should be filmed in an informal setting; videos should be made more animated by the introduction of motion and continuous visual flow, in addition to extemporaneous speaking; instructors should be enthusiastic and speak quite quickly; and lastly, there should be technical support for rewatching and skimming videos.

Similar to Guo et al. (2014), more recent studies have discussed the students' engagement with videos that are delivered by MOOC (Bonafini et al., 2017; Engenes et al., 2020). The findings of both studies showed that videos are core elements of MOOC and the design of online courses. The participants were satisfied with learning by using online videos. In some respects, the results of these studies were quite similar to those of Guo et al. (2014) regarding the length of the video, which should be short, as most of the participants considered the appropriate length of videos to be in the range of 5 to 6 minutes.

Brecht (2012) conducted a study of online video lectures. The aim was to find out and measure the types of learning benefits are provided by video lectures, to gauge students' use and 
acceptance of this form of computer-based instruction, and to compare the results from alternative video designs to show whether learning is affected differently. Three videos were designed to investigate a financial accounting course. The first design paid no attention to the relief and change-of-pace elements, the second video included graphics/cartoons and sounds/music clips, and the third video included a small number of graphics and sounds. The results showed that students use video lectures to receive tutorial help, improve initial learning and course grades, and reduce dropout rates. The results also revealed that the second design received the highest rating for video helpfulness in initial learning and exam revision.

Cross, Bayyapunedi, Cutrell, Agarwal, \& Thies (2013) used a controlled experiment to study several of the effects of video tutorials. After creating Khan-style (tablet drawing) and PowerPoint slide versions of three video lectures, they then planned and conducted an online survey of 150 participants regarding their preferences. Their study revealed that there were advantages and disadvantages to both tutorial styles. Based on their findings, they proposed a hybrid style called TypeRighting, which offers a combination of the benefits of both styles.

Scagnoli et al. (2015) also investigated the use of video lectures in online and hybrid courses. The study detailed the opportunities, challenges, strengths, and weaknesses experienced in developing and implementing this technique. The results showed that undergraduate students' attitude toward the use of fully online video lectures was more positive than that of undergraduates in blended or hybrid courses. In addition, researchers addressed several of the strengths of video lectures, such as motivating learning and giving the students the opportunity to learn concepts in their own time and at their own pace. They also identified several drawbacks of video lectures particularly regarding their creation and implementation; for example, the loss of real life interaction between the students and the instructor.

A comparative analysis was done by Bubaš, Čižmešija, \& Kovačić (2018) between the use of YouTube video recordings of lectures and other types of online learning technologies from the students' point of view. The results indicated that video lectures are one of the highest-ranked tools regarding the aspects of interest, usefulness, information-learning ability, and improved comprehension and long-term retention of course content.

Other similar studies was conducted in the time of COVID-19. For example, Lowenthal, Borup, West, \& Archambault, 2020 described the experiences of four different universities that used asynchronous video to keep engagement and connection during the COVID-19 crisis. For practice and future studies, authors concluded with several observations such as asynchronous video is a good tool to emphasize student reflection, establish emotional connection with students, provide feedback on assignments, and is time-flexible so it could be used for class interactions in different time zones.

All of the above studies created and designed videos and then investigated the students' subsequent behaviour. However, none offered to upload video lectures onto a university website. Therefore, the current study aims to explore several aspects: students' desire to have this kind of media on the university website, the extent to which it will assist them in their studies, their preferences regarding the visual design of these video lectures, how to create a design based on students' opinions, and, finally, we dedicated part of the study to discuss the benefits and contribution of this study findings in time of COVID-19. 


\section{Methods}

The data collection process for this research involved several steps: choosing the relevant participants, obtaining the study material requirements, and then selecting the most appropriate interview approach.

\section{Selection of Participants}

The study started by selecting participants who had the characteristics necessary to achieve the study aims. In order to collect more information on whether cultural differences affect the study results, students from two different universities (one a high-ranking university and one from a developing country) were chosen. Other essential characteristics required of potential participants included the field of study (scientific or humanities studies), as the author discussed the topic of the videos the student watched most.

This study was conducted on 32 students (10 from Swansea University in Wales, UK, and 22 from University of Basrah in Al-Basrah, Iraq) from both undergraduate and postgraduate levels, from both genders (18 females and 14 males), and with ages ranging from 18 to 35 years old. In addition, they were from various university departments. All participants were recruited through an invitation sent via their university email or Facebook messenger. The participants were selected from both the sciences and the humanities (six participants from humanities fields such as psychology and English language and 26 participants from scientific studies fields like computer science, biology, and mathematics). Furthermore, nine postgraduate students and twenty-three undergraduate students participated in order to assess at which level of study these videos are more beneficial and more commonly used. In addition, the participants spoke a range of different languages with seven being native English speakers and the remainder non-native English speakers.

\section{Table 1}

Participants' Demographic Study Domain at Swansea University and the University of Basrah

\begin{tabular}{l|cccccc} 
& & \multicolumn{5}{c}{ Participant Characteristics } \\
University & Male & Female & Post-graduate & Undergraduate & Humanities & Science \\
\hline Swansea & 4 & 6 & 3 & 7 & 2 & 8 \\
Basrah & 10 & 12 & 6 & 16 & 4 & 18 \\
Total & 14 & 18 & 9 & 23 & 6 & 26 \\
\hline
\end{tabular}

\section{Place and Instrument}

The study was carried out in two sites. Ten of the participants were interviewed in various locations in Swansea University buildings in accordance with the most appropriate environment context, such as quietness. The participants were individually interviewed over a period of five days in which two interviews took place per day. The second site was the University of Basrah building where 22 participants were interviewed over a single week.

An audio recorder device was used to record each interview session and save these records to be analyzed later. 


\section{The Process}

The study began by preparing documents, such as the interviewees' ethical rights and the questionnaire. The interview questions were devised to elicit comprehensive, deep, and detailed answers from interviewees. The interview schedule comprised twenty-five concise, open-ended questions, which were organized into three categories: first, general questions about educational videos; second, questions about the visual design; and third, questions about the students' views on such videos being uploaded onto the university website.

The practical steps of the research began after preparing the necessary documents and determining the participants' attributes that were most appropriate to the study. First, an invitation was sent to the target participants via email or Facebook messenger. Once the acceptance had been received, one-to-one individual interviews were held, and the participants were asked the twentyfive questions on the interview schedule.

To start each interview session, the researcher welcomed the participant then stated and explained their ethical rights. Once the interviewee had signed the research consent form, the researcher gave them a questionnaire to fill in, which contained demographic questions regarding, for example, age, field of study, and preferences regarding supportive study materials. In the next phase, the researcher asked the participant the interview questions starting with the general questions to obtain an overview of their overall usage of educational videos, the role such videos play in their studies, how important they are for them, and if they trust the information they provide. Next, the researcher asked the second group of questions, the aim of which is to measure the students' satisfaction with the videos' visual design and delivery format regarding both visual and audio presentations. The final group of questions are intended to obtain information about students' preferences about these videos as full lectures, micro-lectures, or tutorials on the university website and about how they should be designed, for example, the learning subject, style, whether supplementary or essential, and so on. The main aims of these questions were: firstly, to reveal how much educational videos on the university website are acceptable to the students; secondly, to base the design of these videos on their ideas and aspirations. For subsequent transcript and analysis purposes, each interview session was recorded using an audio recorder device and saved as an mp3 file.

\section{Semi-structured Individual Interviews}

The 32 semi-structured individual interviews were conducted to investigate the participants' experiences with videos for learning purposes.

Semi-structured interviews are used to gather focused qualitative textual data. Such interviews are open, thus allowing the interviewer the flexibility to pose new questions during the interview in response to the interviewees' comments (Galletta, 2013). This interview approach also allows the interviewer the opportunity to ask for further clarification if necessary and to pose new questions to obtain a deeper understanding. Since the interviews were not limited to the prepared questions, some sessions took longer than others, as some questions were devised during the interview.

\section{Transcription}

Conducting qualitative study results in large amounts of data. Where the data take the form of audio recorded files, this audio have to be transcribed and converted to a textual form. This study used a phonetic approach for transcription whereby each word, regardless of its importance, was 
transcribed (Biggerstaff \& Thompson, 2008). The aim is to identify the significant ideas suggested by the interviewees and detect those opinions that were repeated or shared by more than one participant. This process produces a number of pages that reflect the discussion session of each individual interview.

\section{Results}

\section{Qualitative Data}

The textual data gained from the transcription were coded using interpretive phenomenological analysis (IPA). This involves close reading and rereading of the text (Smith, Jarman, \& Osborn, 2009). Thus, the text was read repeatedly to ensure the researchers were very familiar with the participants' comments, as each reading might reveal new insights. With each reading, the researchers highlighted points in the interviewees' responses they considered interesting and important (Biggerstaff \& Thompson, 2008). Then, these highlighted texts were divided into smaller notes. The process was continued in order to identify themes and subthemes. The analyzed data were then divided into five themes. The first, participants' overview of their experience with educational videos on YouTube, focused on students' usage of the educational videos in their studies. The second shed light on the benefits of educational videos on YouTube, while the third considered the drawbacks of these videos. The fourth, the descriptive data, focused on the participants' views on the final version of these videos, such as visual design, sounds, and length. The last theme, analysis of the participants' comments about their preferences of having these educational videos on the university website and their suggestions, focused on phrases such as "more useful," "really helpful," and "much better," which indicated the participants" preferences.

After this step, the textual data went to a higher level of abstraction by merging repeated similar or related themes. This phase produced a cluster of master themes, which included subthemes. 


\section{Figure 1.}

Themes and subthemes from one participant after coding process.

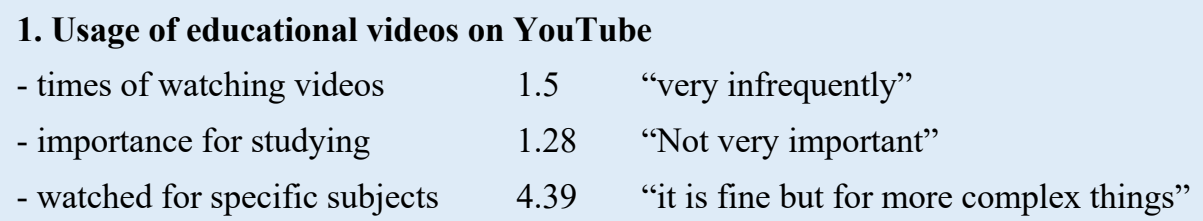

\section{Benefits of educational videos on YouTube}

$\begin{array}{lll}\text { - live demo } & 1.38 \quad \text { "you can see exactly what he was typing" } \\ \text { - provide confidence } & 2.2 \quad \text { "yes I can do it myself" }\end{array}$

\section{Drawbacks of educational videos on YouTube}

- time consuming

- poor understanding

\section{Video design}

- image quality

- show subtitle

-instructor appearance

- background sound

- silent videos

- videos length
2.28 "you would not necessarily find that bit straight away"

2.14 "it is not necessarily help you to understand what it is going on

1.38 "need to be able to read what is on the screen"

4.15 "it is fine without the subtitle"

4.29 “a strange experience isn't it you are listening to somebody you have never met"

4.5 "this amazing sound of birds in the background"

4.38 "less useful for sort of quick things sort of short things"

5.3 "it depends on what you want"

\section{Uploading on university website}

- add to some topic

- videos are helpful

-supplementary
5.7 "useful for certain topic not for all topics"

3.5 "It works surprisingly well for coding"

5.12 "a lot of students will find them helpful"

5.21 "it should not replace the existing teaching"

After the cluster of the first interview had been completed, the same process was repeated for the remaining interviews until clusters of themes for all sessions had been created. Each interview was examined once more simultaneously with the coding process to ensure engagement with the interview text. After the theming and clustering process had been completed for the transcript of all the interview sessions, the next step of the analysis was grouping themes that were common to all the participants to produce a master list, or table, of themes and subthemes (Smith et al., 2009) with quotations from the interviews that demonstrate their views on the use of educational videos on their university website. As the analysis process continued, new themes were added to the master list (Smith et al., 2009). 


\section{Figure 2.}

Master table of themes and subthemes for two participants.

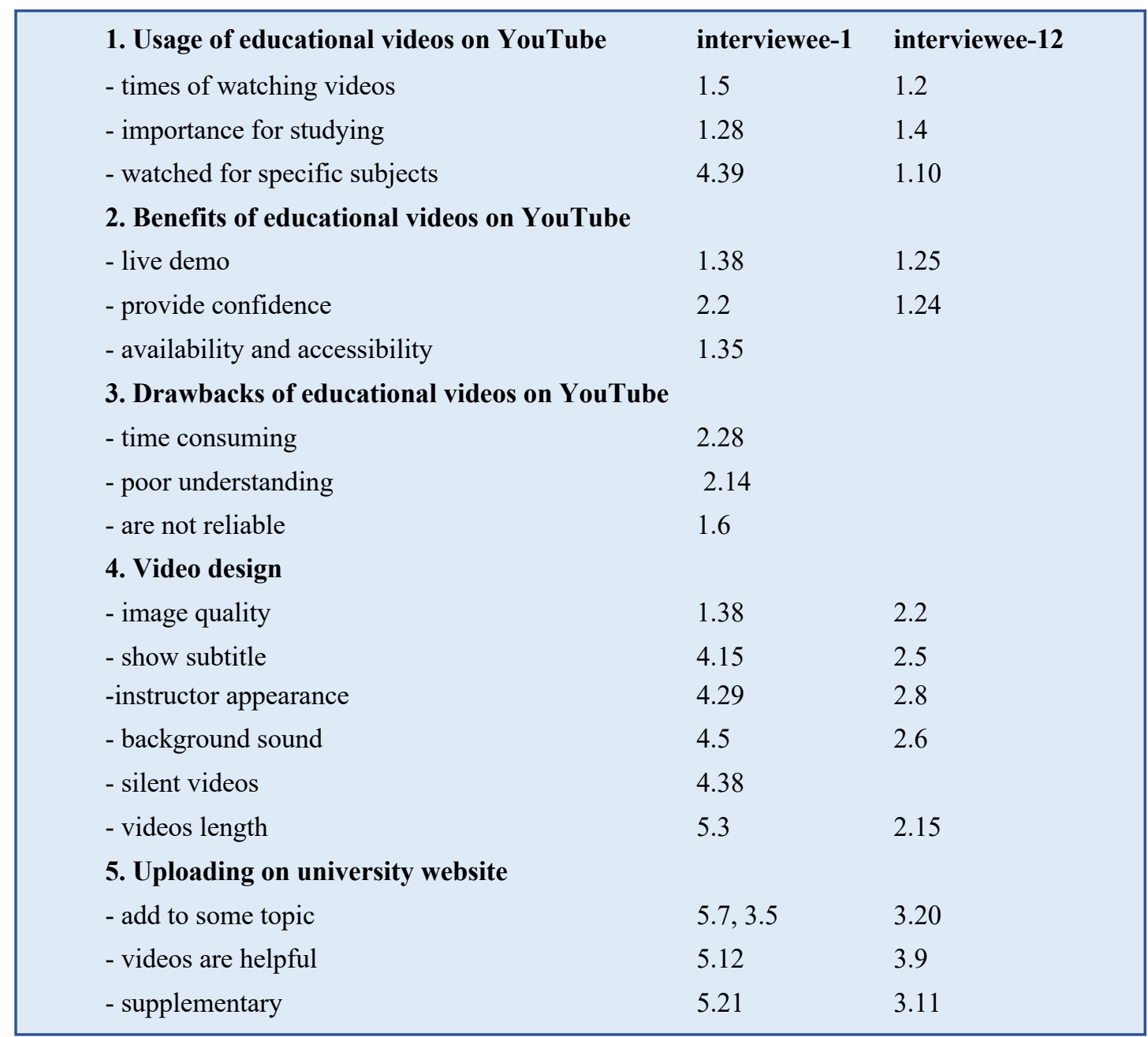

Note: numbers are identifiers which represent the subtheme's appearance in the transcripts in terms of pages and rows.

\section{Results}

Following the analysis phase, five superordinate themes derived from IPA are presented. They offer a rich descriptive of the students' experience with educational videos on YouTube and their preferences regarding the design of effective educational videos that meet their needs.

Initially, students from both universities shared their usage experience of educational videos on YouTube. This included the number of times they watch these videos, the extent to which these videos are important in their studies, and the subjects they watch most. We found that there is good evidence of links between the usages of YouTube educational videos and the type of academic discipline. Students from humanities studies or scientific studies but who came from a humanities studies background admitted that these kinds of videos are unimportant in their studies and they did not use them much. "I use journals most of the time" (Interviewee-15), "Not very important; I do look at online content" (Interviewee-9). The comments from scientific studies 
students supported this finding by illustrating their preferences regarding watching these videos to help them in specific subjects like biology, programming, maths, and engineering; that is, the subjects that belong to scientific fields. "I use them a lot for biology, like, you know, the scientific" (Interviewee-2), "for subjects that have problems, like maths" (Interviewee-12). These students' opinions confirmed that educational videos are beneficial and more effective for scientific subjects rather than humanities. Moreover, in scientific subjects, the visual content is undeniably what keeps students more interested and involved than text books. "It is auditory and visual; it helps you to remember it more" (Interviewee-2), "videos are more interactive than books; the materials become easier to understand" (Interviewee-18). The fact that these kinds of learning sources are both visually and auditory means they engage their audience and capture their attention and they are more memorable than other sources (Higgins, Moeed, \& Eden, 2018).

However, students mentioned some drawbacks of educational videos, which are published on the YouTube. The first issue identified by many participants was that using the online videos is time consuming. "It just takes a while to find the right one" (Interviewee-4). According to the YouTube statistics, more than 500 hours of videos are uploaded to the site every minute (YouTube, 2020). Given the huge number of online videos, students require a long time to find the video that is most useful for them. They switch between videos, as they start to watch the beginning only to find it is incorrect or is only slightly relevant to the topic that they were searching for. Switching and searching for the target video definitely takes a while from students' valuable time. The second issue, which all participants complained about, is the unreliability of these videos. "You do not necessarily know whether this person is really an expert, or have they just uploaded something to YouTube" (Interviewee-1), "I will see then I would not trust them" (Interviewee-3). The source of online educational videos is unknown; for academic research, students need solid evidence. In contrast to published academic resources, students cannot cite videos in assignments, as they do not come from a reputable and reliable source. Currently, many of the videos uploaded onto websites are anonymous. For example, Khan Academy permits instructors to upload videos irrespective of their qualifications or backgrounds (Scagnoli et al., 2015). This made a major concern for the study's participants.

Additionally, the participants were asked several questions related to the presentation of YouTube educational videos. They revealed their experiences with the presentation of these videos in terms of several aspects like image quality, use of subtitles, instructor appearance, silent videos, and the length of these kind of videos. Some participants experienced a poor image quality in some videos they watched. "Yes, a lot, and that was too disappointing and couldn't get the clear idea of $i t$ " (Interviewee-17). They felt dissatisfied and disappointed with these kinds of videos. Not surprisingly, especially when online videos were depending heavily on their visual rendering, image quality should be in very good quality to clear the idea of the video. Beside image quality, students experienced silent video. "I tend just to click them off because I cannot hear; I would rather someone, like, say it and explain it" (Interviewee-27). All students from both universities agreed that videos that lack any vocal explanation are not effective. In support of this view, Ou, Joyner, \& Goel (2019) noted educational video, which displays instructor's writing along with their voiceover, recreates natural features of an in-person classroom.

In terms of showing subtitles, the study revealed similar opinions from students. While seven of the participants were English native speakers, some lacked proficiency in the English language. Nonetheless, it was suggested that subtitles be used with videos to help students who had a poor level of English language should they not fully understand what the tutor is saying: "Not me 
personally because I do not need it but let's say for someone whose English is not as strong as a native speaker; then it will be better for them " (Interviewee-2). The results obviously showed being a native English speaker or non-native speaker does not affect the results, as all students preferred providing subtitle with educational videos.

Furthermore, participants highlighted the length of the videos in their discussion of educational videos, with all of them preferring short videos to long ones. "I do not mind, like, a 10-minute video - not too short because I tend to forget it" (Interviewee-2), "I prefer short videos, so I don't get bored" (Interviewee-31). Speaking of educational video length, experts firmly think that six minutes is the optimal length for educational videos; after six minutes students' engagement will drop rapidly as the video length increased (Guo et al., 2014). However, participants in this study preferred videos to last from 10 to 20 minutes. Furthermore, some participants stated that if the video was too long, they would skip certain parts: "it has to contain what I need I skip parts I just find the appropriate parts to me" (Interviewee-22). However, this meant they lost the real meaning of the video, thus rendering it ineffective. Consequently, a significant number of the interviewed students avoided long videos and selected short concise ones, as they felt the aim should be to provide information quickly for a particular task instead of giving many ideas at one time. In the latter case, the video loses its focus and becomes confusing and unhelpful. "I don't prefer videos that have lots of talking that I don't need or giving a lots of ideas at the one time, which can make me confused or I can't still focus" (Interviewee-17).

The fifth driven main theme was the students' preference regarding uploaded educational videos on their university website. They discussed several aspects in terms of this theme. They expressed their desire to have these kinds of videos on the university website. "I think it would be really helpful" (Interviewee-25). All the participants agreed that having educational videos on the university website would be useful and helpful for many students. But, they preferred to use these videos in some subjects rather than others. The subjects that are scientific and considered to be complex. For example, regarding computer science: "It does very well with programming" (Interviewee-21), "I found them very helpful for complex topics" (Interviewee-15). This finding supports the previously mentioned finding that educational videos are mostly used for scientific subjects.

Although interviewees said having videos on the universities' Blackboard will provide positive impact for students, they were concerned about the possibility of these videos replacing the existing lecture slides. As the videos offer live explanations, this could mean that students no longer attend lectures. "I think it would be a bad thing if instead of going to class, you just give them links to a number of videos" (Interviewee-8), "Then people might just not attend the lectures if they were recorded" (Interviewee-22). However, some participants expressed a preference for educational videos to replace the existing slides of lectures, claiming that this would help students who were unable to attend the lectures: "If the student is sick or they cannot move because they are disabled or in wheelchair and it more difficult for them to attend" (Interviewee-4). Currently, during COVID-19 pandemic, educational videos have become essential to continue learning. Because of limits on individuals' gatherings and lockdowns, all students cannot go to universities and attend face-to-face lectures. During this time, universities' administers are obliged to offer their learning materials through digital media, and create educational videos that meet their students preferences. 


\section{Discussion}

\section{Study Observations}

The study was conducted to explore the students' experience with educational videos which could be found on YouTube. Some observations were drawn on the study findings which were made by analyzing the students' opinions.

Firstly, the most important issue that was addressed in this study is the unreliability of YouTube educational videos. Based on the participants' beliefs, the results confirm that the information delivered by these videos lacked accuracy. Unlike books and journals, they cannot rely on these videos as sources for their studies. Similar to the current study, some past studies approved the poor information quality and unreliability of online commercial videos (Toolabi, Parsaei, Elyasinia, \& Zamanian, 2019; Springer et al., 2020; White, Latour, Giordano, Taylor, \& Agarwal, 2020). However, these previous studies were restricted to one specific subject, namely, medicine. In this study, we confirmed the unreliability for these videos in various subjects like computer science, marketing, literacy, and many more.

Because of the unreliability of educational videos, which was demonstrated by several studies (Toolabi et al., 2019; Springer et al., 2020; White et al., 2020), these studies recommended monitoring the educational videos that are uploaded onto the internet. Some of them suggested that only government institutions have the right to create and upload these kinds of videos. This study proposed uploading educational videos onto universities' websites, as these websites are controlled, monitored, and authorized by academic professionals. It is a suitable solution to overcome the unreliability issue and increase students' trust in these kinds of videos. Moreover, many participants mentioned that searching through the internet to find the right video is difficult and time-consuming. Lowenthal et al. (2020) agreed with this opinion. The authors stated that having asynchronous videos outside of the learning management system is a challenge for students and it would be easier for them if these videos were embedded in a learning management system. Thus, by placing these videos on the university Blackboard, students will find the related videos immediately, which will streamline the searching process and save the students time.

Secondly, the study approved that educational videos are more preferable for scientific subjects. Based on the students' opinion, our study showed that online educational videos are more effective in the scientific discipline rather than humanities. The fact that scientific subjects are rich in diagrams, formulas, equations, and figures makes them more dependent than the humanities on visual and auditory explanations (Higgins et al., 2018). Educational videos that strongly offer these two features with live demonstrations will help visual/auditory learning-style students to respond well, maintain their attention, and enhance their memory (Higgins et al., 2018). Further, the study dedicated a significant part to extract detailed information about students' preferences in terms of the design of online educational videos. In order to create successful learning objects, it is necessary to have detailed knowledge of how users interpret and interact with the various parts of the multimedia design (Persson, Wattengård, \& Lilledahl, 2019). Students from our study had experienced different styles of videos: silent/vocal videos, long/short videos, with/without subtitles. Most of the students expressed a preference for vocal, short, and subtitled videos to keep their attention and engagements with educational video. In terms of the ideal length of educational video, there was a slight difference between the results obtained from this study and past researches. While our study proved that videos that were 10 to 20 minute are the students' most preferred to keep them focus and engaged, Guo et al. (2014) confirmed that 6 minutes is the ideal 
length for an educational video and the attention would drop after this number. Another research revealed that the majority of students will not watch an educational video for more than 15 minutes (Berg, Brand, Grant, Kirk, \& Zimmerman, 2014). Regardless of the optimal number for a video length, all studies, including ours, agreed that short videos are best for producing engaging material. Therefore, experts recommended to trim the lecture contents and record mini-lectures (Berg et al., 2014). In addition to the video length, we found some other characteristics, which are in line with other studies suggestions, should be considered to create an effective e-learning video, such as, presenting the video along with instructor's voiceover (Ou et al., 2019), showing the instructor face (Wang, Antonenko, \& Dawson, 2020), and adding subtitles to the video (Jae, 2019).

The final exploration of this study is universities' ranking does not affect students' opinions. Despite the study having been conducted with students from two different universities (a highly ranked university and one from a developing country), the findings were fairly similar. Students from both universities gave similar views on most of the study aspects. For example, YouTube educational videos are not reliable, the videos should not be too long, and educational videos are more effective for scientific modules. Some previous studies investigated students experience with educational videos in different universities, such as Lowenthal et al. (2020). However, these studies were limited to universities from one country; for example, Lowenthal et al. (2020) chose students from the American universities only. Moreover, Dean \& Lima (2017) preferred to include views from international students to elevate the sample responses. Thus, this research tried to fill the lack of past researches by investigating views of students from totally different universities, and in two different countries. However, this difference did not make a bias in the results, as students from both universities (Swansea University and University of Basrah) had similar opinions.

\section{The Design of Educational Videos}

The study aims to explore the experiences of students in two universities with educational videos. Design implications will be suggested based on the study's results and findings. The intended design will be included on university websites under each module content. However, not all modules will have these videos, as the results of the study have shown that this kind of videos is more effective for scientific and practical subjects. Thus, they will be more prevalent in scientific modules, such as mathematics, biology, computer science, and so on. These videos should be a maximum of 20 minutes long to explain the key terms of subjects related to the module topic. The topics of the videos should be structured around the module topics to facilitate the search process for the students. Currently, it often takes students a long time to find the video that is most useful for the topic they are seeking. Therefore, including relevant educational videos on the university websites reduces the time students spend searching for these materials. The videos' visual design should be simple but usable. If the video is in the format of a PowerPoint presentation, instructor's voice should be added to re-create natural features of an in-person classroom.

As has been already discussed, reliability is the greatest concern students have with educational videos. Firstly, to increase the students' trust in the information that the videos provide, these videos should be included on the university website only once the module lecturer has approved them and particularly if the videos are recorded by the module instructor. Moreover, we suggest attaching the references the video is based on to increase the reliability of these videos. 


\section{Figure 3.}

The educational video prototype based on the study findings.

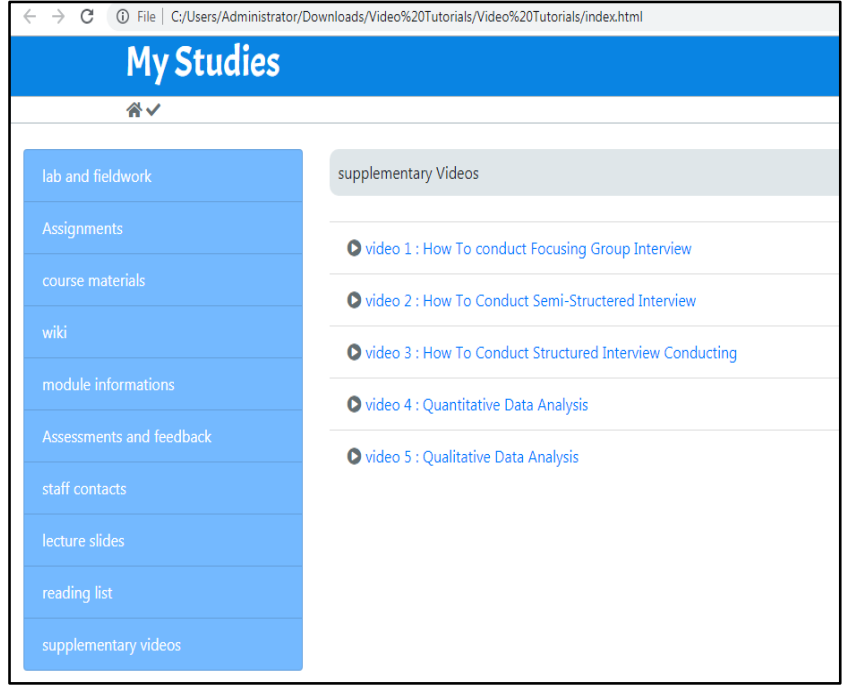

(a)

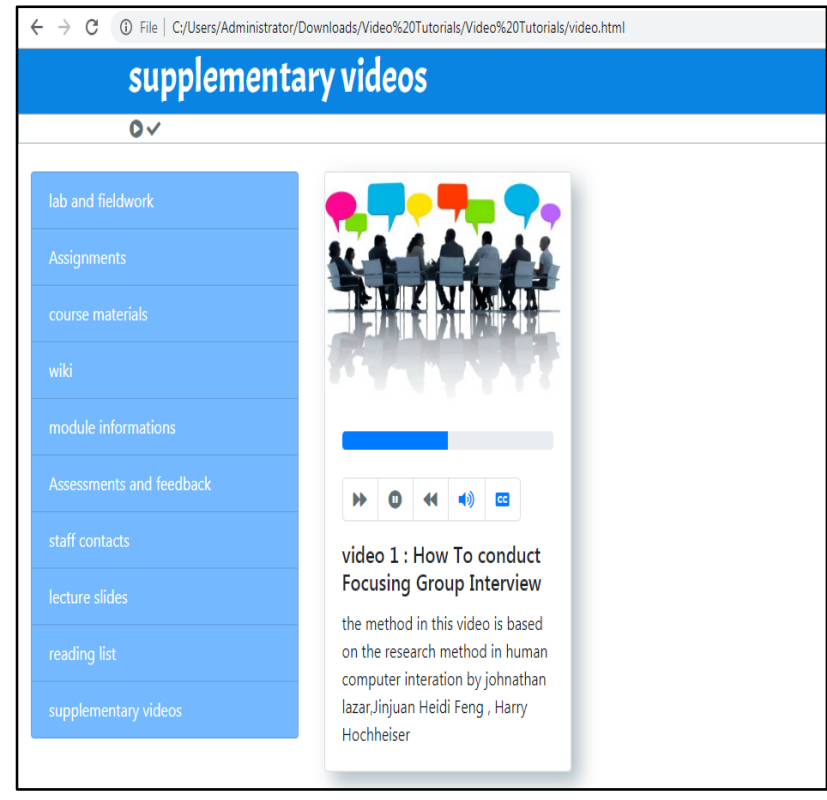

(b)

Note: image (a) is the module page where a list of videos is shown when the student clicks on the "supplementary videos" tab. Image (b) is the designed video that contains all aspects that participants referred.

\section{Educational Videos in the time of COVID-19}

During the COVID-19 pandemic, many governments are introducing policies that restrict the number of individuals gathering in the same place. Such policies have changed the normal functioning of academic institutions. Therefore, the leaders of these institutions have had to adopt alternative methods for learning when it is not possible for students to attend schools and universities. Most of these institutions took the quick decision to move to online learning for the remainder of the 2019 academic year. However, they still face the challenge of declining enrolment in 2020. A recent survey by Turk, Salazar, \& Vigil (2020) showed the majority of college presidents put summer and autumn enrollment at the top of the most critical issues in the face of COVID-19.

Online videos have become an essential component to maintain the learning process during the pandemic. Studies like Lowenthal et al. (2020) proved that asynchronous video helps to maintain students' connection and engagement during the COVID-19 pandemic. They could help college presidents to deal with declining enrolment by offering their courses via digital media. However, to ensure videos are effective and are helping students, it is necessary to take a closer look at their design.

Before the pandemic, some studies, like Buchner (2018) and Ou et al. (2019), attempted to investigate the principles of designing effective educational videos. The authors offered several recommendations to be followed when designing educational videos. However, these studies were 
based on theoretical investigations and did not involve students, who are the main users of educational videos. In contrast, the investigation that this study has conducted is based on the students. We conducted interviews and analyzed real data derived from students' answers. Therefore, our proposed video prototype completely matches real students' preferences. As a result, if this prototype is adopted by academic institutions, it will increase the enrollment percentage. Students will find video lectures that meet their expectations, and that will encourage them to register with and enroll in these institutions. Moreover, since the study was conducted at two different universities (a highly ranked university and a university from a developing country), the findings and the proposed video prototype could be useful to and adopted by different universities regardless of their ranking.

\section{Conclusion}

Currently, technology infiltrates all aspects of life. It is used in healthcare, marketing, transportation, education, and so on, and it can be used to enhance students' understanding and knowledge. Therefore, attempts have been made to facilitate teaching even if the students are in distant locations.

This paper has explored the use of YouTube, arguably the most popular video website, to host a range of videos including videos for learning purposes. Then it examined students' experiences with educational videos. Participants were thirty-two students from two different universities who shared their views about such videos. They gave their opinions individually through semi-structured interviews. Each interview was recorded and then transformed into textual data, which were analyzed using the IPA method, where themes and subthemes were identified.

The study has provided several significant findings related to, for example, the appropriate duration of the video, the kind of subjects that benefit from the use of videos, and the issue of reliability. A suggested design has been created in accordance with these findings.

Finally, the study has discussed the problem of declining enrollment faced by academic institutions during COVID-19. Since the study is based wholly on students (the ideal audience for educational videos), the findings and the proposed educational video prototype could be beneficial

and could assist in creating effective videos that will potentially encourage students to enroll during the pandemic. 


\section{References}

Abdelmseih, M. (2016). Evaluation and reliability of YouTube videos for age-related macular degeneration (amd) - A warning sign! Journal of Clinical \& Experimental Ophthalmology, $7(5), 1-8$.

Berg, R., Brand, A., Grant, J., Kirk, J. S., \& Zimmerman, T. (2014). Leveraging recorded minilectures to increase student learning. The Teaching Professor. Online Classroom, 14(2).

Berk, R. A. (2009). Multimedia teaching with video clips: TV, movies, YouTube, and MTVU in the college classroom. International Journal of Technology in Teaching and Learning, 5(1), $1-21$.

Biggerstaff, D., \& Thompson, A. R. (2008). Interpretative phenomenological analysis (IPA): A qualitative methodology of choice in healthcare research. Qualitative Research in Psychology, 5(3), 173-183.

Bonafini, F. C., Chae, C., Park, E., \& Jablokow, K. W. (2017). How much does student engagement with videos and forums in a MOOC affect their achievement? Online Learning, 21(4), 223-240.

Brecht, H. D. (2012). Learning from online video lectures. Journal of Information Technology Education:Innovations in Practice, 11, 227-250.

Bubaš, G., Čižmešija, A., \& Kovačić, A. (2018). Comparative analysis of the use of video lectures and web 2.0 applications in a hybrid university course environment: A case study. EUNIS 2018 Annual Congress. Paris, France.

Buchner, J. (2018). How to create educational videos: From watching passively to learning actively. Open Online Journal for Research and Education (12), 1-10.

Cha, M., Kwak, H., Rodriguez, P., Ahn, Y.-Y., \& Moon, S. (2007). I tube, you tube, everybody tubes: Analyzing the world's largest user generated content video system. Proceedings of the 7th ACM SIGCOMM Conference on Internet Measurement, 1-14.

Cooper, B. (2007). Central issues in the use of computer-based materials for high volume entrepreneurship education. Active Learning in Higher Education, 8(3), 201-217.

Cross, A., Bayyapunedi, M., Cutrell, E., Agarwal, A., \& Thies, W. (2013, April). TypeRighting: Combining the benefits of handwriting and typeface in online educational videos. In Proceedings of the SIGCHI Conference on Human Factors in Computing Systems (pp. 793-796).

Engenes, I., Nohr, M., Singh, A. B., \& Mørch, A. (2020). Use of videos in the Information and Communication Technology Massive Open Online Course: Insights for learning and development of transformative digital agency with pre- and in-service teachers in Norway. Policy Futures in Education, 18(4), 497-516. 
Ferhatoglu, M. F., Kartal, A., Ekici, U., \& Gurkan, A. (2019). Evaluation of the reliability, utility, and quality of the information in sleeve gastrectomy videos shared on open access video sharing platform YouTube. Obesity Surgery, 29, 1477-1484.

Foertsch, J., Moses, G., Strikwerda, J., \& Litzkow, M. (2002). Reversing the lecture/homework paradigm using eTEACH web-based streaming video software. Journal of Engineering Education, 91(3), 267-274.

Galletta, A. (2013). Mastering the semi-structured interview and beyond: From research design to analysis and publication. NYU Press.

Guo, P., Kim, J., \& Rubin, R. (2014). How video production affects student engagement: An empirical study of MOOC videos. Proceedings of the First ACM Conference on Learning@ Scale Conference, 41-50. Association for Computing Machinery.

Higgins, J., Moeed, A., \& Eden, R. (2018). Video as a mediating artefact of science learning: cogenerated views of what helps students learn from watching video. Asia-Pacific Science Education, 4(6), 1-19.

Jones, T., \& Cuthrell, K. (2011). YouTube: Educational potentials and pitfalls. Computers in the Schools, 28(1), 75-85.

Karakas, E., \& Tekindal, S. (2008). The effects of computer-assisted learning in teaching permanent magnet synchronous motors. IEEE Transactions on Education, 51(4), 448-455.

Kunjambu, K., \& Muniandy, P. (2013). A content analysis in the studies of YouTube in selected journals. Procedia-Social and Behavioral Sciences, 103, 10-18.

Latchman, H. A., \& Latchman, S. M. (2001). Lectures on demand in ALN: Enhancing the online learning experience. Online Learning, 5(1), 85-98.

Lowenthal, P. R., Borup, J., West, R. E., \& Archambault, L. (2020). Thinking beyond Zoom: Using asynchronous video to maintain connection and engagement during the COVID-19 pandemic. Journal of Technology and Teacher Education, 28(2), 383-391.

Marshall, J. M. (2002). Learning with technology: Evidence that technology can, and does, support learning. https://pdfs.semanticscholar.org/04c7/cf116a8f378bad4d9966277f527d11378fa3.pdf

Martinho, M., \& Pinto, M. (2012). Scholars' YouTube channels: Content analysis of educational videos. Internet Latent Corpus Journal, 2(2), 76-90.

https://www.researchgate.net/publication/232747160_Scholars'_YouTube_channels_conten t_analysis_of_educational_videos

Ou, C., Joyner, D. A., \& Goel, A. K. (2019). Designing and developing video lessons for online learning: A seven-principle model. Online Learning, 23(2), 82-104. 
Persson, J. R., Wattengård, E., \& Lilledahl, M. B. (2019). The effect of captions and written text on viewing behavior in educational videos. International Journal on Math, Science and Technology Education, 7(1), 124-147.

Scagnoli, N. I., McKinney, A., \& Moore-Reynen, J. (2015). Video lectures in eLearning. Handbook of Research on Innovative Technology Integration in Higher Education, 115134.

Smith, J. A., Jarman, M., \& Osborn, M. (2009). Interpretative Phenomenological Analysis. In M. Murray \& K. Chamberlain (Eds.), Qualitative health psychology: Theories and methods (pp. 53-80). SAGE.

Springer, B., Bechler, U., Koller, U., Windhager, R., \& Waldstein, W. (2020). Online videos provide poor information quality, reliability, and accuracy regarding rehabilitation and return to sport after anterior cruciate ligament reconstruction. Arthroscopy: The Journal of Arthroscopic \& Related Surgery, 36(7).

Toolabi, K., Parsaei, R., Elyasinia, F., \& Zamanian, A. (2019). Reliability and educational value of laparoscopic sleeve gastrectomy surgery videos on YouTube. Obesity Surgery, 29, 28062813.

Turk, J., Salazar, M. C. S., \& Vigil, D. (2020). College and university presidents respond to COVID-19: April 2020 survey. American Council on Education. https://www.acenet.edu/Research-Insights/Pages/Senior-Leaders/College-and-UniversityPresidents-Respond-to-COVID-19-April-2020.aspx

Vidergor, H. E., \& Ben-Amram, P. (2020). Khan academy effectiveness: The case of math secondary students' perceptions. Computers \& Education, 157.

Wang, J., Antonenko, P., \& Dawson, K. (2020). Does visual attention to the instructor in online video affect learning and learner perceptions? An eye-tracking analysis. Computers \& Education, 146.

White, M. D., Latour, K., Giordano, M., Taylor, T., \& Agarwal, N. (2020). Reliability and quality of online patient education videos for lateral lumbar interbody fusion. Journal of Neurosurgery, 34(6), 1-6.

YouTube. (2020). YouTube by the numbers. Retrieved August 19, 2019, from https://www.youtube.com/yt/about/press/ 